\title{
UNINTENDED EFFECTS OF SOCIAL PROTECTION PROGRAMMES IN ZAMBIA. A CASE OF CHILD GRANT CASH TRANSFER PROGRAMME $(\text { CGP })^{1}$
}

Isaac KABELENGA2 ${ }^{2}$, Fumbani MPHANDE ${ }^{3}$

DOI: 10.35782/JCPP.2019.3.04

\begin{abstract}
This qualitative study explores the unintended effects of social protection programmes in Zambia. By studying Child Grant Programme (CGP) in one rural community, the study indicates that the effects of the CGP in the rural community are broader than what was anticipated by the Zambian government and its international and local development partners when embarking on the programme. From the results, it is evident that the effects of the CGP transcend the primary beneficiaries. This is because it has also benefited the whole rural community and business individuals and entities that trade with the rural community. The study concludes also that the new knowledge generated in this study has been made possible with the use of qualitative research. Thus, the findings of this study provide strong support for the importance of calibrating the methodological approach with the underlying aims of the study.
\end{abstract}

Key words: unintended effects of social protection; CGP; rural community; Zambia; qualitative research

\section{Introduction}

At the turn of the millennium, social protection has emerged as one of the most widely debated socio-economic development agendas for most states of the global South and

\footnotetext{
${ }^{1}$ NOTE: Small part of the materials used in this article may appear in International Congress on Afro-Eurasian Research Publications either for 2019 or 2020. The paper titled: Linkages between Social Protection and Community Development: Empirical evidence from one rural community of Zambia may be submitted to the Congress for publication. Some materials on descriptions of the rural community and study findings are similar to the ones contained in this article. We plan to submit the paper to the Congress before the end of 2019.

$2 \mathrm{PhD}$, Lecturer, University of Zambia, School of Humanities and Social Sciences.; E-mail: isaackabelenga@gmail.com

${ }^{3} \mathrm{Mr}$, Lecturer, University of Africa, Faculty of Education, Lusaka; E-mail: fmphande@gmail.com
} 
among member states of the international donor community in the global North. This shift began in the late 1990s, driven by disenchantment with the results of the World Bank and International Monetary Fund (IMF) structural adjustment programmes (SAPs), the 1997 Asian economic crisis, and a heightened awareness of the negative effects of global poverty (Samson, 2013). Thus, the World Bank promoted social protection as a key component of international poverty reduction strategies (social risk management). It is also seen by many countries in the global South as one of the essential tools for achieving Sustainable Development Goals (SDGs) (François-Xavier, 2013). It is also considered both a basic human right and a social investment. This is because it enables people to enjoy their right to social protection and achieving human development (ILO, 2008).

While I acknowledge that studies on the impacts of social protection have been undertaken across the world, the studies have focused mainly on assessing whether the primary objectives of social protection have been achieved or not. Some of the primary objectives are provided below in the section titled 'effects of social protection'. Few studies have focused on investigating the unintended effects of social protection on local communities where particular social protection programmes are implemented (Nyasha, Knowles and Davies, 2013; François-Xavier, 2013). Thus, the gap exists in the scientific knowledge on the unintended consequences of the social protection programmes at different levels of society especially in the global South where the concept of formal social protection is relatively new (ILO, 2010). This gap motivates the basis for writing this paper.

\section{Effects of social protection}

In the available literature, among the commonly documented intended effects (that is, the primary objectives) of social protection programmes include the following: First, it reduces extreme poverty and the intergenerational transfer of poverty with the following as some of the specific ways in which social protection reduces poverty: Income: it supplements and not replaces household income. Education: it increases the number of children enrolled and attending primary and secondary school education. Health: it reduces the rate of morbidity and mortality among the targeted beneficiaries such as the children under five years old, disabled people, the people living with HIV/AIDs and other chronic diseases, and older people among other commonly poverty-stricken categories of people in many countries globally. Food security: it increases the number of households having a second meal per day. Livelihood: it increases the number of households owning assets such as livestock (ILO, 2010; François-Xavier 2013). For example, in Latin America, there is evidence that the Mexican government social assistance programme (PROGRESA programme) created in 1997 increased school attendance and grade progression (Independent Evaluation Group (IEG) of the World Bank, 2011). Similarly, evidence from Nicaragua's Atención a Crisis programme (2005-2006) combined a conditional cash transfer with either vocational training or a productive investment grant (non-agricultural) has shown that the programme increased income diversification and provided greater protection from drought than basic conditional cash transfers (François-Xavier, 2013). Studies undertaken in Africa have also shown similar effects. For instance, in Zambia, 
Seidenfeld and Handa (2011) have established that the CGP have important impacts on diet diversity and food security of eligible recipients. For example, the study established that 78 percent of the CGP transfer went to food spending, 7 percent to fuel and 5 percent to health. Within food, 34 percent of the increased spending on food went to cereals, 24 percent to meats and 18 percent to fruits and vegetables. In Ethiopia, evaluative studies on Productive Safety Nets Programme (PSNP) and Other Food Security Programme (OFSP) have shown that beneficiaries had the improvements in food security, better agricultural technologies and participation in non-farm business enterprises (ILO, 2010).

Although most of the studies globally are biased towards the intended effects of social protection programmes (François-Xavier, 2013), handful studies on the unintended consequences of social protection have been undertaken in some countries (Nyasha, Knowles and Davis, 2013). Notable include studies by Yap (2008), Angelucci and De Giorgi (2009), FAO (2010), IEG (2011), François-Xavier (2013) and Nyasha, Knowles and Davis (2013). For example, a small number of studies hints at the link between social protections interventions and increased participation in social networks of reciprocity, in which poor households manage risk via informal exchanges or transfers among extended family, friends and neighbors. In Mexico, Angelucci and De Giorgi (2009) and IEG (2011) found that the PROGRESA programme increased the flow of private transfers to non-beneficiary households in target communities by 33 percent as compared to non-beneficiary households in control communities. In Brazil, studies by Yap (2008), FAO (2010), IEG (2011) and François-Xavier (2013) reported negative externalities such as increased child labour in ineligible households from Brazil's Child Labour Eradication Programme (PETI). This was attributed to the increase in local wages for child labourer when beneficiaries decrease their participation in child labour. In Niger, a short-term cash transfer programme with wide coverage and a significant payment size produced temporary inflation in the prices of edible oil and milk in the context of a market with high transaction costs and poor supply-side information (François-Xavier, 2013)). In India where National Rural Employment Guarantee Scheme (NREGS)'s wage is above the local casual labour rate, people were encouraged to withdraw from exploitative casual labour (for example, bonded labour), which was perceived by the majority of the local people as a desirable shift and an improvement. Notwithstanding this unintended positive change, other studies on NREGS have established that interventions like cash for work programmes distort local wage markets. This happens if programme owners pay wages that are higher than the prevailing rates, as these could create labour deficits in other productive sectors and those sectors negatively get affected (IEG, 2011; Nyasha, Knowles and Davis, 2013).

From the above unintended effects, it is evident that social protection interventions in different countries have effects that extend beyond the beneficiary household into the local community and economy (FAO, 2010). Notwithstanding this, François-Xavier (2013) reports that most social protection impact evaluations do not assess spillovers. This aspect is usually overlooked in study designs. In recognition of this gap in scientific knowledge, Nyasha, Knowles and Davis (2013) argue that the lack of solid evidence on the broader impacts of social protection is not surprising since most researchers rightly focus on determining whether social protection programmes have 
achieved their immediate primary objectives of reducing vulnerability, increasing food security, and/or enhancing human capital development. However, these ways of study limit scientific knowledge (François-Xavier, 2013). This is because researchers leave out other important effects of social protection programmes which can open new ways of thinking especially when designing, implementing, monitoring and evaluating social protection programmes. To broaden scientific knowledge on the impacts of social protection programmes, it is important to document also the unintended impacts. FAO (2010) and Nyasha, Knowles and Davis (2013) advice that having empirical evidence on the broader productive impacts of social protection instruments could help many countries in the global South where the social protection agenda has received little political support from politicians and other policy makers on the ground that they think that positive effects of social protection on the development of their countries are minimal. For example, if additional benefits are shown, political leaders and other policy makers can be enabled to understand the trickle-down benefits of intensifying and scaling up social protection programmes. In turn, this can help in mobilizing political will that is much needed in many countries in the global South to extend coverage and sustain social protection programmes (ILO, 2010; Samson, 2013).

In light of the above knowledge gaps, the aim of this study was to explore the unintended effects of the Child Grant Cash Transfer Programme (CGP) in Zambia with focus on one rural community where the programme was implemented. Below are details of the programme:

CGP has been implemented in Zambia since 2010 in three districts which have the highest rates of under-five stunting, wasting, morbidity and mortality in the country. The districts are Kalabo, Kaputa, and Shang'ombo. The CGP targets any household with a child under five years old and disabled children aged five up to fourteen years. Its specific objectives are similar to the ones for other social protection programmes in other countries across the global South. These are: to supplement and not replace household income; to increase the number of children enrolled and attending primary school education; to reduce the rate of mortality and morbidity among children under five years old; to increase the number of households having a second meal per day; and to increase the number of households owning assets. The funders for this programme are the Government of Zambia and International Donors which include UK Department for International Development (DFID), Irish Aid and United Nations Children Fund (UNICEF) among others. Eligible households receive 60 Kwacha (roughly U.S. \$12) per month regardless of household size and households with a disabled child received double that amount. Payments are made bimonthly and there are no conditions attached to the grant for one to receive the money. The programme uses universal approach in its delivery. This means that all the eligible households in the targeted communities receive the grant on bimonthly basis and wean-off when children turn either five years or fourteen years if has disabilities. In terms of governance and administration, the CGP uses government structures at the district and area local community levels to manage and administer the program in beneficiary communities. These include District Social Welfare Officers, Area Coordinating Committee (ACC) and the Community Welfare Assistance Committee (CWAC). The ACC is a sub district structure that covers 8 to $12 \mathrm{CWACs}$. The CWAC is a community-level structure which 
covers 20 up to approximately 500 households. The ACC comprises members from the respective CWACs and is responsible for verifying potential and actual beneficiaries, monitoring the performance of the CWACs, and handle grievances. The CWACs comprise members from the community and are responsible for raising awareness about the CGP, identify beneficiary households, communicate details about payments with households, and counsel beneficiary households (Zambia's Ministry of Community Development, Mother and Child Health, 2013).

\section{Fieldwork}

\section{Study site}

This study was carried out in one rural community of Zambia where the Government of Zambia and various development partners implemented the CGP. Because the informants were assured that their names will not be mentioned anywhere, the actual name of the rural community where this study took place, names of the informants and actual dates for the study will not be mentioned. Instead, the community is just called as 'rural community' and the informants are abbreviated either as informant.1, informant.2, focus group discussion (FGD).1, FGD.2 or as informant during community meeting. However, the actual verbatim which came from the interview data are maintained. In this article, the word community is used by the informants to denote a group of people living together in one geographical area, and thus they understand their local environment better. The descriptions of the community are as follows: Its total population was estimated to be around 92, 000 of which the majorities are children below 18 years and the youths. It had a government basic school, government health centre and old government gravel road. In terms of livelihoods, the community members mainly depended on subsistence farming, fishing, and selling traditional drinks. However, the common community problems experienced included poor road nets, long distances to social services like educational and health facilities (many inhabitants walked about 9 kilometers), illiteracy, malnutrition, disease, mortality, lack of access to credit facilities and food insecurity due to geographical factors such as droughts or floods among other social problems (Zambia's Ministry of Community Development, Mother and Child Health, 2013). From these descriptions, it is clear that the whole rural community was vulnerable to many risks and shocks at the time of fieldwork.

\section{Informants and research methods}

Informants were community-dwellers. These were the primary beneficiaries of CGP and mainly mothers who had children aged below five years and handful mothers with disabled children between zero and fourteen years and other stakeholders who were involved in the implementation of the CGP in the rural community. It also included a few community members who were not on the programme because they were either outside catchment area or they became community members after the programme had already started. When collecting data, the study utilized qualitative research methodology to allow for the voices of the primary beneficiaries and other stakeholders to be heard. Because little is known about the unintended effects of CGP in Zambia, 
especially from the experiences and conceptions of the beneficiaries and other stakeholders in the rural community, this grounded approach was preferable (Yin, 2011; Kabelenga, 2017). One of the distinguishing features of qualitative inquiry is that it allows new insights about the particular issue under investigation to be generated. This comes about because the researcher studies the respective phenomenon in depth with the local people with first-hand information and experiences of the phenomenon under study in their local communities.

Actual data collection was done by conducting five one to one in-depth interviews (IDIs) with the primary beneficiaries, three focus group discussions (FGDs) with government officials at the rural community level, and CWAC members. On average, each FGD had 8 participants. Additional data was collected during one community meeting with 100 community members that comprised some primary and non-primary beneficiaries. As used in this paper, the term community meeting is used to mean that local people who lived in that rural community gathered together at one place to share with researchers their views and experiences about the CGP. Inclusions of the non-primary beneficiaries in the meeting were meant to get their views about the effects of being non-beneficiaries of CGP. A total of 129 community members participated in the study. Recruitment of informants was through purposeful and convenient selection (Creswell, 2006). Informants were located through community invitation letters and door to door notifications using CWACs members. The invitation letters described the research project, presented the discussion topics, and included information that the interviews were to be recorded. Three FGDs were held in places chosen by the informants notably a government office, school classroom and a church building. On the other hand, the community meeting was held under the tree. The five one-to-one IDIs were conducted in village huts for each informant. The main research questions which were asked are: what are some of the positive changes that have come about due to the implementation of CGP in this community? How the whole community is positively affected due to the implementation of CGP? How about the negative effects? What recommendations can you make to the Zambian government and other stakeholders involved in CGP on how to maximize the benefits of CGP in the development of this community? The informants were also informed that they were free to leave the interview at any time. The interviews were recorded and lasted between 60 to 90 minutes. Participants were also encouraged to contact the researchers through their telephone numbers after the interview if needed (Erlingsson, Saveman \& Berg, 2005).

Besides the advantages of qualitative research talked about, FGDs, IDIs and community meetings enabled the researchers to explore, clarify and triangulate the informants' views. This is because these data collection methods allowed researchers to probe on many issues and compared constructions as they unfolded during interviews. In that way, researchers were able to establish divergences and convergences in the constructions of the phenomenon studied (Creswell, 2006).

\section{Data Analysis}

The interview text was analyzed by means of qualitative thematic analysis. Analysis involved several steps. First, researchers listened to the audio interviews and read the 
transcripts straight through to get a sense of the whole. The general impression was that the participants discussed the intended and unintended positive effects of the CGP as well as the suggestions on how to scale up the benefits of the CGP. In the data, no informants brought out any negative effects of the CGP. Intended effects that emerged from the interview data were reduction of hunger among the households of the beneficiaries, improving access of the beneficiary households to social services such as health and education; and addressing maternal and child morbidity as well as mortality among households of the primary beneficiaries. Unintended effects were bringing local, national and international institutions together in addressing the social problems faced by the rural community; linking up the rural community to public, private and other community resources; and enhancement of business opportunities for the rural community members and other members of the Zambian society. In this paper, the focus is on unintended effects of the CGP. Thus, the second step involved sorting each interview text using the above three themes of the unintended effects as a framework. Third, the researchers critically analyzed, questioned, and compared text passages in each theme to achieve credible and trustworthy reasonableness (Guba, 1981). Representative statements from the interviews have been used to illustrate the themes. These statements are referred to by the nature of the interview. Erlingsson, Saveman \& Berg (2005) advise that the foundation for credibility lies also within the examples of statements from the original texts offered in the findings section. Fourth, the researchers compared the results from all the informants and reflected on and discussed the findings. Fifth, in order to make the findings become analytical, researchers used the concepts of relationships and power as analytical tools to interpret the data.

These concepts were chosen after critical reflections upon the data. That is, all the issues that the informants brought out seemed to revolve around the above two scientific concepts. In social sciences, there are no universally agreed upon definitions of the two concepts. This is because concepts are socially constructed and are constantly in state of flux (Berger \& Luckmann, 1991). Notwithstanding this, in this study the concepts of power and relationship are used to mean the following: Power is the ability of one person or institution to influence the behavior of another person or institution to do something for which they would not have done if they were just by themselves (Weber 1957; Foucault, 1980; Mahajan, 2003). On the other hand, relationship is used to denote a wide array of interpersonal, inter-institutional and intracommunity interactions between and among the rural community members, rural community institutions, with other members of the Zambian society and national and/or international institutions aimed at bringing about positive change in the rural community (Osei-Hwedie \& Mwansa \& Mufune, 1990).

\section{Findings}

There was a general consensus among all the informants that the CGP had produced positive effects that transcend the primary beneficiaries. That was because despite the CGP being meant for the welfare of the children, the whole rural community and other individuals that interacted with the rural community had benefited. Analysis of the interview text resulted in identification of three unintended effects: bringing local, 
national and international institutions together in addressing the social problems faced by the rural community; linking the rural community to public, private resources and other community resources; and enhancement of business opportunities for the rural community members and other members of the Zambian society. Detailed information on each of these effects is provided below:

\section{Bringing local, national and international institutions together to address social problems faced by the rural community}

One of the most interesting finding that emerges from the data is that, the implementation of the CGP has brought about the situation where various institutions within and outside the rural community have come together to address the social problems faced by the community. For example, informants report that CGP falls in the Ministry of Community Development and Social Services as well in the International Donor Community; health centers fall in the Ministry of Health; schools fall in the Ministry of Education; and CWACs are the local community structures. However, with the implementation of the CGP, all these institutions have simultaneously come together and are working hand in hand in ensuring that local people actively participate in addressing their problems. For instance, one male informant during the community meeting explained the effects of CGP in this way:

"We are now working together in addressing various problems faced by this community. Many local people for example never used to give birth from the clinic or send their children to school. Most of them never. This has changed. All the institutions such as education, health, Department of Social Welfare, and local people have come together as a result of this grant and are making sure that mothers deliver from the bealth centre if they are to stand any chance of getting the grant. And those with children who are receiving the money send children to school. Before coming of the CGP, this never used to happen. Maternal and child mortality have even reduced. Life expectancy and literacy levels in this community are going up. So, the whole community has benefited. This is what we call community development - addressing community problems."

Informants brought out similar effect during FGD.2:

Researcher: So, what changes has the CGP brought about in this community in general?

Informant.1: Many institutions are now working together.

Informant.2: That is very true. For example, one cannot register a child on CGP if they don't have under-five clinic card.

Informant.1: And the card can only be gotten if one delivers from the clinic. The CWACs are making sure that all the mothers in this community adhere to this requirement.

Informant.4: To me that means that community apathy in accessing maternity services is being reduced.

Researcher: why is community apathy reducing?

Informant.4: Our women know that if they don't deliver from clinics, the child will not have clinic card, and that may make it difficult to be registered on the programme.

Informant.3: It is not just women, even husbands know that

Researcher: So even husbands have no option but to send their wives to the clinic? 
Informant.5: Yes. And that is beneficial to the whole community. Because the community is not losing community members through death which is common when women give birth from their villages.

The above data can be interpreted using the concepts of community relationships, family relationships, community power and family power. That is, from the above data, it can be deduced that the informants hold the view that CGP is working as a catalyst for enhancing community relationships and community power in mobilizing the local people to join local, and national efforts in addressing their community problems. From the data, it is evident that these interactions have also impacted positively on family relationships and family power. This is because family members have been enabled by the CGP to join local community and the whole nation in addressing their problems and for the whole local community. This is because from the above episodes, informants hold the view that as a result of improving community and family relationships and powers, the CGP has resulted in marrying the efforts of the Zambian government and the local community in encouraging community members for example to access health care and education services. This means that from the views of the informants, though the primary aim of CGP is not to improve community and family relationships, CGP has impacted positively on the whole community by improving local community and family relationships with the Zambian government and its development partners. This is also improving the powers of the families and the whole community to actively participate in addressing family and community problems.

\section{Linking the rural community to public, private and other community resources}

In all the three data collection methods used in this study (that is, FGDs, IDIs and community meeting), informants reported that CGP was working as a strategy for linking the rural community to productive resources essential for individual and community development. By productive resources, informants meant those resources that made beneficiary households and the whole community to develop. In the data, it is evident that the resources are provided by the public and private sectors as well by the rural community members. The productive resources commonly brought out by the informants are the loans, fishing nets, labour and firewood. For instance, it was learnt during the study that the beneficiaries of the CGP found it easier to access loans or fishing nets on credit than those who were not receiving the grant. That was because lenders were confident that the beneficiaries of the CGP would be able to pay back the loan and/or pay for the fishing nets once they get the child grant. Beneficiaries also find it easier to hire labour from the local community either to help them till their farms or to help them transport their merchandize from their fields to the local market. That enhanced individual productivity and for the whole community. That was because fishing, subsistence farming and petty trading which were the main economic activities for the whole rural community had improved. For instance, community members who were not on CGP complained in this way during the community meeting:

"It is easier for our colleagues who are on CGP to get a loan than for us who are not on CGP. If lenders see that one is trustworthy, they also give them their goods on credit and then 
they pay them when they have money. That is making our friends to be more productive than us who are just struggling on our own."

Informants during FGD.3 also bring out the similar effect:

"Many beneficiaries of CGP have become productive. As already said, others have started small businesses; some are even getting small loans; others hire labour to belp them fetch firewood which they use when making tradition drinks and some use it to transport firewood from the forest to the salt industries."

Beneficiary mothers during IDIs also hold the similar view like their counterparts who participated in the FGDs and community meeting:

"This grant is helping us a lot. For single mothers like us, we find it very difficult to transport firewood on the heads from the forests to here [fields]. This is because firewood is very heavy. So with the grant, you can hire someone say who has the bicycle or who is energetic to belp you fetch and transport firewood and also transport our merchandize to road sites where we have customers [motorists] who buy our goods. This is making most of us to be productive." (IDI.3).

"It is abit easier for us to get a loan from people with money in the neighborhoods. This is because lenders know that once we get the money, we will be able to pay back. If you get that loan, most of us use it to start small businesses like making flitters, buy fish which we re-sale or ask someone to belp you till your farm land." (IDI.5).

The above data can be interpreted using the concepts of individual power and relationships of trust. This interpretation is based on the ground that from the above episodes, it is evident that informants hold the view that the CGP has enhanced the abilities of the beneficiaries to have access to productive resources, which in turn are making them to become economically productive. Relationships of trust are evident in those expressions where informants disclose that lenders are more willing to give loans to recipients of the CGP than non-recipients. In the views of the informants, one of the sources of the relationships of trust between the lenders and the recipients of the loans arise from one's being the recipient of the CGP. From the episodes, it is clear that from daily interactions with their local environments, the above relationships make beneficiaries of the CGP to be more productive than non-beneficiaries.

\section{Enhancement of business opportunities}

Another unintended effect that emerges from the data is that the CGP has enhanced business opportunities for the rural community members and other members of the Zambian society. By business opportunities, informants mean trade opportunities that make individual community members, the whole rural community and other members of the Zambian society to develop. Informants during community meeting, FGDs and IDIs reported that although the CGP is meant for households with children, the whole rural community and a number of business individuals and houses both within and outside the rural community had benefited from the CGP in that the grant had opened up the whole rural community to business opportunities which positively impacted on the socio-economic development of individuals and the whole rural community. Informants cite establishment of more local trade opportunities as some of the specific 
ways through which the CGP has brought about business opportunities to the local community. Informants report that following the implementation of the CGP, many business houses and individuals from within the local community and across Zambia especially from the urban cities are bringing their merchandize to the local community. This is because traders know that the majority of the local people have money received from the CGP and thus have financial abilities to buy their merchandize. In the process of trading with the local people, additional business opportunities have been opened up for the whole local community. For instance, informants disclose that, business houses and individuals from the cities also buy various goods produced by the local people such as farm produce like pumpkins, cassava, beans, and groundnuts among others as well as livestocks like goats and chickens. These interactions are encouraging the local people to be productive. For instance, the local people are encouraged to venture in various agricultural activities and fishing because they know that they would easily sale their products to the business houses and individuals who bring their merchandize to the recipients of the CGP. During community meeting, one female informant brought out the effects of the CGP as follows:

"I have nothing to say against the CGP. All we can say are just praises. This grant has benefited this community in various ways. In addition to what other people have already said, another benefit is that this grant has opened up this community to various business opportunities both from within this district and across Zambia. Many people doing business are now coming to this community to sale their goods to the beneficiaries of the grant. But in the process, they also become our market. For example, they buy from us things like fish, goats and farm produce. Our colleagues who do fishing, they also ask these business people to help them buy fishing nets from the towns. This is because in this community, we do not have shops that sale fishing nets. This is making most of us to work hard because we know that once I produce something, I will easily sell it to these people who target beneficiaries of the grant."

Similar voice tones are heard from the informants who participated in FGDs:

"The local and urban business houses usually come to this community to sell their merchandize to the beneficiaries of the CGP. Many times, they also allow the beneficiaries of the CGP to get the merchandize on credit and pay them when they receive the child grant. These interactions between this poor community and rich communities never used to bappen before the CGP was introduced”. (FGD.1).

During separate IDIs with the beneficiary mothers, individual informants also agree with the views expressed by other informants during community meeting and FGDs:

"Life is now abit easier. When you have something to sell, you can easily do so. Our friends with money from cities do buy from us. So, we no longer struggle to sale our produce especially chickens, goats, honey, birds. All these business people have been brought here due to the coming of the CGP. You can actually get surprised if you stay in this community. These business people even know the time we receive the grant. So they usually come here either before beneficiaries begin to receive their grants or when beneficiaries are receiving the money. During their time of stay in this community, they get involved in other business opportunities with the local people like buying fish, chicken and goats. So, this is creating market for the whole community." (IDI.1). 


\section{"We now have business. These businessmen and women who come in this community due to grant also buy from us fish, groundnuts and chickens.” (IDI.4).}

The above data can be interpreted using the concept of business relationships. That is, from the above expressions, it is self-explanatory that the informants hold the view that CGP has enhanced business opportunities for some of the local people. This is because, in all the above episodes, it is clear that the CGP has resulted in connecting some local people such as those with farm produce, livestocks, and those involved in fishing to business opportunities, both from within and outside the local community. As can be evidenced from the above verbatim quotes, enhancements of business relationships have dominated all the informants' voices. This means that the informants are of the view that the positive effects of the CGP are not only felt by the people within the local community, but also those from outside the local community and in particular business houses and individuals who come to do business in the local community following the implementation of the CGP.

\section{Discussions}

When all the findings of this study are condensed together, it is evident that all the informants share the view that the CGP has positive spillover effects to the whole local community and the Zambian society. The effect of creating social capital brought out by the informants if linked to the existing literature agrees with the studies undertaken by Angelucci and De Giorgi (2009) and IEG (2011) in Latin America which established the stronger links between social protections interventions and increased participation in social networks of reciprocity. For example, in Mexico, they established that PROGRESA programme had resulted in increasing the abilities of beneficiary households to manage risk via informal exchanges or transfers among extended family, friends and neighbors. The results also are in tandem with the studies by FAO (2010); and Nyasha, Knowles and Davis (2013) which established that social protection interventions if well designed and implemented have effects that transcend the beneficiary household into the local community and national economies. For example, in Ghana, Nicaragua and India, the studies showed that the positive impacts were also being experienced by non-beneficiary households, who got linked to beneficiary households through local markets. Whilst such links can sometimes be exploitative to the beneficiary communities as business individuals and entities can take advantage of the beneficiaries by for example, selling sub-standard merchandise to the people in beneficiary communities at exorbitant prices (Kabelenga, 2010), from the findings of the current study, it is evident that such interactions are good for the whole community as they have resulted into linking up beneficiary community and households of the beneficiaries to new ideas, new business opportunities, and exposure to the outside local community which are essential for the development of individual community members and the whole community. In development discourses, these 'social networks' are part of the recommended ingredients for individual and local community development (UN, 1982; Ose-Hwedie et.al, 1990; Putnam, 1993). One strategy that has dominated debates about the idea of community development in the context of third world countries is the idea of sharing progressive ideas among development partners on how to bring about development (UN, 1982; Osei-Hwedie, Mwansa \& Katembula, 
1990). From the current results, it seems that this idea is being ignited and realized with the introduction of the CGP in the rural community. In the views of the informants, these interactions have enhanced productivity of the local people and growth of the economy of the whole rural community.

Interesting also is that when the current findings are thought about in the context of literature on community development, it is evident that the CGP in the rural community of Zambia is acting as a catalyst for community development. One of the strategies for community development is joining the efforts of many people together in addressing community problems (Osei-Hwedie, Mwansa \& Katembula, 1990). This is the case of the results of this study. This is because from the results, it is evident that through CGP the Zambian government and international donors have mobilized the cash and other technicalities, and then the local people themselves have contributed their labour. It is this mixture of efforts that have waged war against community problems in the rural community and resulting into improving the well-being of the whole community. From the results, it can also be deduced that one of the reasons that explain the impacts experienced in the local community is that the CGP is designed in the manner that allows the local, national and international community development actors to work with each other rather than one actor working for the other in addressing community problems. This linkage further underscores the community development adage that says that 'big things happen at teamwork' (Osei-Hwedie, Mwansa \& Katembula, 1990: 40). From the episodes, it seems that the informants agree with each other that 'big things' in their community had happened because of the teamwork which had been created and catalyzed by the CGP.

\section{Conclusions}

Based on the findings of this study, the following are the conclusions: To begin with, the results indicate that the effects of the CGP in the rural community of Zambia are broader than what is documented in many literatures. From the episodes provided by the informants it is evident that effects of the CGP transcend the primary beneficiaries. This is because CGP has not only positively affected the intended beneficiaries, but also benefited the whole rural community and business individuals and entities that trade with the rural community. This is evident in that CGP has brought out the following changes which the Government of Zambia and its development partners never anticipated when introducing the CGP: bringing institutions together in addressing local community problems; linking up the rural community to developmental resources; and enhancement of business opportunities This entails that this study has broadened the current discourses on the effects of social protection. For instance, although this study was undertaken in one rural community, it has brought in new perspectives in scientific literature. One perspective brought in by the episodes is that in the contemporary world, one ingredient that can be used to foster local people's participation in rural community development work is the provision of CGP in a universal manner. It has also brought in the perspective that for local people to participate in local community development work, they calculate the benefits that would accrue to individual participants and to the whole community. From this study, it seems that both forms of benefits - that is 'individual benefits' and 'communal benefits' 
are considered important by individual participants. Combinations of the two forms of benefits can enable many local people to be willing to participate in local community development work. International Science Council (2004) and Creswell (2007) advise that one of the greatest contributions of any piece of scientific research to scientific knowledge is changing people's thinking about a particular phenomenon. By bringing in scientific literature new perspectives on the unintended consequences of CGP, our assumption is that many readers of this article will acquire and develop new ways of thinking about the consequences of CGP. Thus, it is our hope that this article will spark intense scientific debates and reflective practice-oriented discourses on how social protection can foster individual, local community and national developments.

From this study, it is also evident that the factors that have made CGP to catalyze local community development are the provision of the CGP using universal approach, designing the programme in the manner that allows all the development actors to work together throughout the whole programme cycle, designing the programme in the manner that allows local people to directly and indirectly benefit from the programme as individual participants and as a local community, consistent and timely provision of social protection benefits to the beneficiaries as well as provision of the benefits for sustained period of time. This results in continuous interactions of all the development actors in addressing local community problems.

This study concludes also that the new knowledge generated in this study has been made possible with the use of qualitative research. That is, by allowing the research methodology that allows the local people to freely unfold social issues in their local communities using their own words, experiences, cultural connotations and using their own thinking, new knowledge has been generated (Berger \& Luckmann, 1991; Creswell, 2006). Thus, the findings of this study provide strong support for the importance of calibrating the methodological approach with the underlying aims of the study. Particularly in instances where research is intended to develop a deeper description and understanding of the phenomenon under study, qualitative research become the best alternative (Kabelenga, 2018).

Although this study has generated new knowledge and thus broadened scientific knowledge (International Science Council, 2004; Creswell, 2006), it is also important to acknowledge its limitations. Since this qualitative study was undertaken in one rural community of Zambia, it limits the transferability of the findings to all the communities in Zambia where social protection programmes are being implemented. Similarly, participants within each FGD knew one another. This could have meant that the participants already had a shared system of values and similar opinions that might have limited the diversity and richness of the discussions (Erlingsson, Saveman \& Berg, 2005). Notwithstanding these limitations, it is interesting to note that results that emerged from community meeting, FGDs and one-on-one IDIs did not dramatically vary from each other. Ideally, this increased the trustworthiness (Guba, 1981) of the study.

Given its limitations, however, few previous studies have been undertaken on the unintended effects of social protection programmes on local communities where they are implemented across the world (FAO, 2010; Nyasha, Knowles \& Davis, 2013; 
François-Xavier, 2013). This study has contributed knowledge towards filling up this gap. However, due to its limitations, continuing research is recommended on the unintended effects of different types of social protection programmes on individual beneficiaries, households of the beneficiaries, local communities, implementing institutions, on ruling and opposition political parties, on nations where the programmes are implemented and on international donors that fund part of social protection programmes especially in the global South like Zambia. Mixed methods approach may be a more suitable when conducting further research in this area. This may allow both breadth and depth of the effects to be captured. We hope that this study has put into place one more piece of the puzzle that will one day result into showing the global picture of the unintended effects of different social protection programmes in both the global North and global South.

\section{Acknowledgments}

We sincerely appreciate the Government of Zambia and its development partners such as UNICEF, DFID (UK), FAO, Irish Aid, Friedrich Ebert Stiftung (FES), University of Zambia and Platform for Social Protection Zambia as well as Southern Africa Social Protection Experts Network (SASPEN) and University of Johannesburg that allowed us to participate in various social protections programmes. The exposure motivated us to write this article.

\section{References}

Berger, L.P. \& Luckmann. T. (1991). The Social Construction of Reality: A Treatise in the Sociology of Knowledge. Thousand Oaks: Sage Publications.

Creswell, W.J. (2006). Second Edition Qualitative Inquiry \& Research Design - Choosing among Five Approaches. London: Sage Publications Ltd.

Erlingsson,C.L, Saveman, B.I and Berg, A.C .(2005). Perceptions of Elder Abuse in Sweden: Voices of Older Persons. Brief Treatment and Crisis Intervention. 5 (2).

FAO (2010). Food Security and Social Protection in Africa. New York: United Nations

François-Xavier M. (2013). Social Protection as Development Policy: A New International Agenda for Action. International Development Policy, p. 89-106.

Foucoult, M. (1980). Power/Knowledge: Selected Interviews and Other Writings 1972-1977. London: Harvester Press.

Guba, E.G. (1981). Criteria for assessing the trustworthiness of naturalistic inquiries. Educational Communication \& Technology Journal. 2, 75-91.

IEG (2011).

ILO (2008). Can Low-Income Countries Afford Basic Social Security? Social Security Policy Briefings. Geneva: ILO.

International Science Council (2004). The V alue of Basic Scientific Research. Paris: UNDESA.

Kabelenga, I. (2010). Rural-Urban Linkages Seminar Paper. London: London School of Economics and Political Science.

Kabelenga, I. (2017). Understanding elder abuse in rural and urban Zambia using the concept of of extended family. Journal of Anthropological Researches and Studies, no.5, 47. 
Kabelenga, I. (2018). Elder Abuse in Rural and Urban Zambia - Interview study with community leaders. Rovaniemi, Acta Universitatis Lapponiensis, 372.

Majahan, V.D. (2003). Political Theory. New Delhi: Sterling Publishers. McCord, M. (2004). Cash Transfers and Political Economy in Sub-Sabaran Africa. Project Briefing No. 31. London: Overseas Development Institute.

Ministry of Community Development, Mother and Child Health. (2013). Social Cash Transfer Scheme: 24-Month Impact Report for the Child Grant Programme. Lusaka: American Institutes for Research.

Nyasha, Knowles \& Davies (2013). See article Social protection and community development

Osei-Hwedie, K., Mwansa, L., and Mufune, P. (1990). Youth and Community Work Practice Methods, Techniques and Skills. London: Commonwealth Secretariat

Putnam, D. R. (1993): Making Democracy Work: Civic Traditions in Modern Italy. New York. Princeton University Press.

UN (1982). Community Development - Encouraging Local Initiatives in Africa. New York

Samson, M. (2011) Impacts of South Africa's Child Support Grant. In S. Handa, S. Devereux \& D. Webb (Eds.), Social Protection for Africa's Cbildren. New York, Routledge.

Weber, M. (1957). The Theory of Social and Economic Organization. Free Press. Glencoe, III.

Yin, R.K. (2003). Case Study Research, Design and Methods. Calif: Sage. 